\title{
Degassing and layers variation effect on composite processing by vacuum assisted resin transfer moulding
}

\author{
Alpa Tapan Bhatt, Piyush P Gohil* and Vijaykumar Chaudhary \\ Mechanical Engineering Department, Faculty of Technology \& Engineering, The M.S. University of Baroda, Vadodara, Gujarat, India \\ *Corresponding Author: push4679@yahoo.com
}

Submitted : 17/03/2020

Revised : :13/02/2021

Accepted : 20/02/2021

\begin{abstract}
Vacuum assisted resin transfer moulding (VARTM) is a fibre reinforced composite (FRC) making process, in which resin is impregnated to fabric by application of vacuum. This process is also known as vacuum infusion process. The critical issue in VARTM process is void generation. Voids form due to variety of reasons, most of which can be avoided. Vacuum degassing is one of the solutions that reduce the air entrapped inside resin during impregnation. In this work, six laminates from jute and polyester resin were prepared, three with degassing and three without degassing with variation in number of jute layers 5, 10, and 15, respectively. Microscopic examination and mechanical properties have been observed before and after degassing. It was observed that degassing improves mechanical properties of composite laminates and reduces void content. It was observed that the thickness variation in laminate increased as the number of layers increased.
\end{abstract}

Keywords: Degassing; Fiber reinforced composite; Mechanical properties; Vacuum infusion void.

\section{INTRODUCTION}

Vacuum Assisted resin transfer moulding (VARTM) is a process in which resin is impregnated inside the fabric, and vacuum is used to generate the pressure difference. There are many variants of VARTM like VARI, RIFT, SCIMEN, RI, etc. (Van Oosterom et al., 2019 \& Heider and Gillespie, 2010). This process has advantages like being comparatively economical, and large structures can be manufactured, with only one side tool required, and neat process and complicated shapes are possible (Schledjewski and Grössing, 2016 \& Bhatt et al., 2018). The challenges are to control void content and part thickness variation for high end applications like aircraft.

The objective of this paper is to study the effect of degassing and how it improves the mechanical properties and controls void inside the laminate. The effect of increasing number of layers in thickness variation is also been studied. 
In this paper, a total of six laminates were prepared with changing number of layers 5,10 , and 15 . The effect of degassing was studied with mechanical characterisation and micro void visualisation. The thickness variation of cured laminate was observed to study the effect of increasing number of layers. It was observed that degassing plays an important role to improve mechanical strength and control void content. Moreover, as the number of layers increased, the thickness variation increased.

The schematic diagram of VARTM process is shown in Figure 1. The glass table was used to lay jute fabric, Peel Ply, and high permeable distribution media (HPM). The full assembly was covered with vacuum bag and sealed with sealant tape. Full vacuum was supplied for 15 minutes for applying dry compaction to the fabric. After leak check, the resin was impregnated. Resin after impregnation started moving from resin supply location to vacuum supply due to pressure difference. The flow velocity was observed during impregnation through top camera.

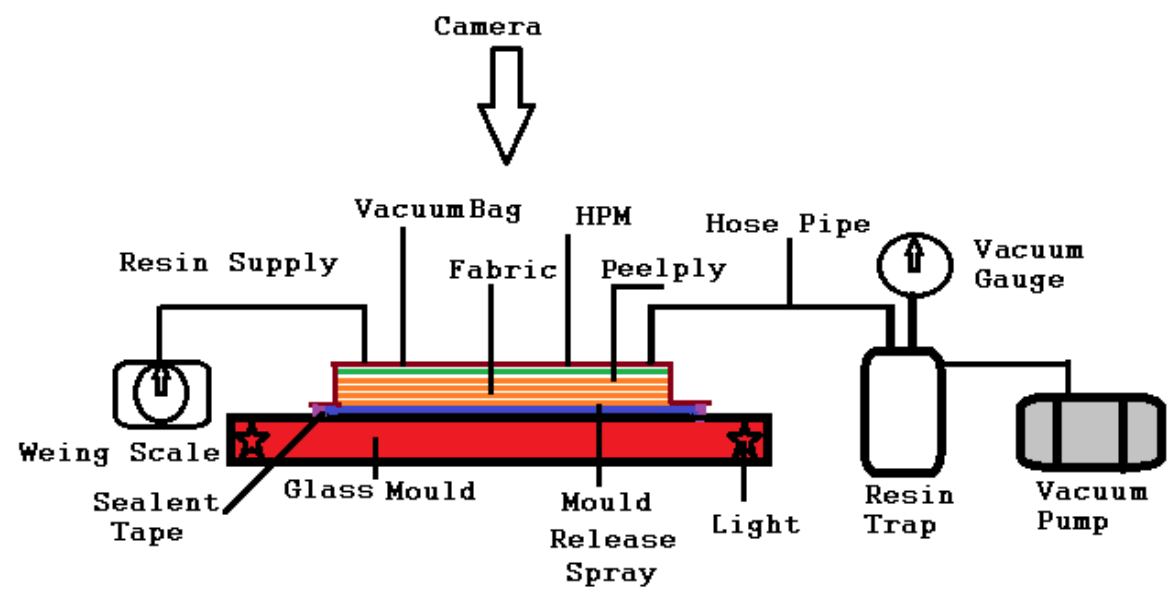

Figure 1. Schematic diagram for developed VARTM experimental setup.

The mechanical characterisation was performed, and it was found that degassing has improved mechanical strength. It is important to degas resin for critical structures like aircraft, wind blade, etc. to avoid void content.

\section{RESEARCH REVIEW}

Degassing is necessary to remove air entrapped inside the resin before actual impregnation. Bolick (2000) explained that well degassed resin reduces air pockets. Brouwer et al. (2003) discussed that reasons for void could be reinforcement permeability, dissolved gases in resin, shrinkage of resin, and leakage at sealant tape. According to him, the standard method to degas the resin was by applying vacuum. Kazmi et al. (2019) worked on controlling the part quality for vacuum infusion process. Void content was measured microscopically.

Li et al. (2004) concluded that the void generates due to entrapped air during infusion, leakage in vacuum bag, staging of resin, entrapped air in fibre bundle, or curing. They suggested good practices such as vacuum debulking, degassing, location of vent at last of fill, and optimizing resin cure. Prasad (2004) performed degassing by keeping resin at room temperature in vacuum chamber at high vacuum for an hour, again heating at $65^{\circ} \mathrm{C}$ for 30 minutes to reduce viscosity. To make the resin bubble free during infusion, Afendi et al. (2005) suggested degassing methods, which include normal degassing, bubble nucleation agent method, and air spray method. 
Ghose et al. (2009) modified the thermal cycle to reduce void content from $7 \%$ to $3 \%$. Kedari et al. (2011) performed degassing at 0.336 bar for 15 minutes at room temperature. They informed that void formation may depend upon vacuum pressure, mould temperature, flow pattern, porous size, and dual scale flow behaviour media. Amirkhosravi et al. (2019) could achieve reduction in void content by $1 \%$ using stationary and movable magnets for dry compaction. Yalcinkaya et al. (2019) could achieve reduction in void content up to $1 \%$ achieved by applying 138 Pa gauge pressure on vacuum bag for high temperature VARTM process.

Park and Woo (2011) studied modelling of void formation and concluded that void was formed due to heterogeneous nature of fabric, mechanical air entrapped, nucleation, leakage, cavitation, uneven resin curing, etc. They talked in detail about micro and macro bubble generated within and between tow. They called them as tow void and channel void. Dewan et al. (2013) used jute and polyester resin and performed degassing of resin before and after mixing it with MEKP and cobalt. They calculated void content as per ASTM D273-9M.

Yalcinkaya et al. (2017) confirmed that degassing was important before curing and hence they also performed degassing of resin for 2 hours for epoxy and hardener mixture. Grimsley et al. (2019) performed degassing on epoxy resin for one hour in full vacuum at room temperature.

From the above review it is clear that degassing definitely helps reduce void content and also improves the strength of laminate. Requirement of degassing depends on how much air is entrapped inside the resin. Degassing without air entrapped inside the resin has no meaning.

\section{MATERIALS AND METHODS}

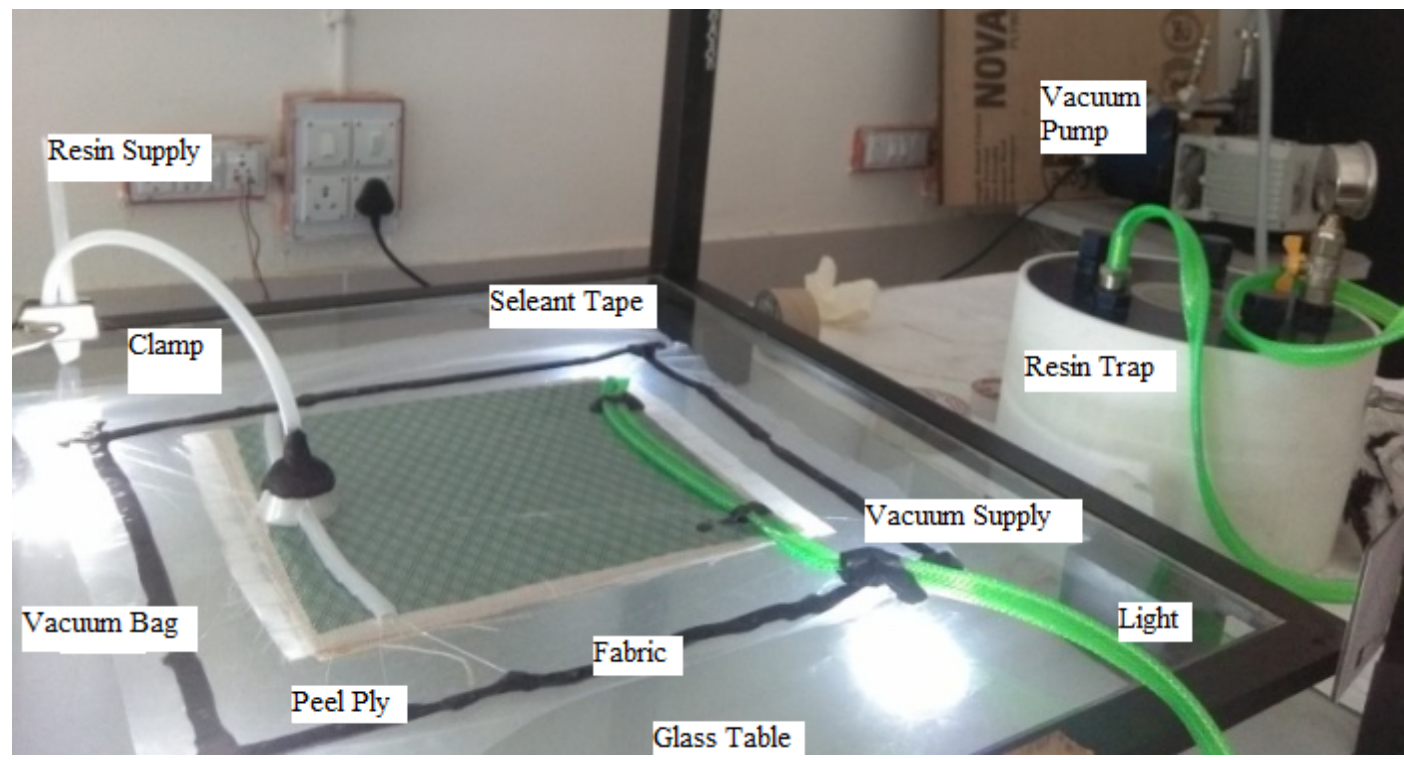

Figure 2. Developed experimental setup.

Six experiments were performed to study the effect of degassing and variation in number of layers in VARTM process. $0.290 \mathrm{~kg} / \mathrm{m}^{3}$ plain weave jute layers of $0.3 \mathrm{~m} \mathrm{X} 0.3 \mathrm{~m}$ were cut and were laid on glass table after cleaning with acetone and applying three coats of mould release spray. Three laminates of layers 5, 10, and 15, respectively, 
were impregnated without degassing, and the same numbers of layers were again impregnated with degassing at full vacuum.

The degassing was done in resin trap for 3 minutes after mixing the polyester resin with hardener (MEKP) and accelerator (cobalt) in ratio of 100:1:0.5. The jute fabric was chosen because it is natural, eco-friendly, and available in India. The polyester resin was selected because it is easily available and economical thermoset resin.

The jute fabric was enclosed with Peel Ply and high permeable media (HPM). The full assembly was covered with vacuum bag and sealed with sealant tape. Vacuum supply was provided from one end and resin from the other side. The flow would be considered as 1D linear flow from left to right. Two cameras were used to see the flow behaviours, flow time and through thickness flow. The experimental setup is shown in Figure 2.

The dry loading was done to ensure that there is proper compaction during actual impregnation and to achieve uniform part thickness. The resin was taken double than fabric to ensure proper impregnation of resin inside fabric and to ensure no dry patches in laminate. The clamps were used to close the system after impregnation. Vacuum was kept on until the resin was cured. The full assembly was cured for 24 hours at room temperature.

Various measurements were performed during and after impregnation. The flow velocity was measured during impregnation. After curing, each laminate was taken out, weighed and thickness measurement was done to check the variation on part thickness. The laminate was also observed under microscope with 180X magnification lance. After this, the test coupons were cut from laminate to check its tensile and flexural strength.

\section{MESUREMENT}

For each laminate, flow velocity, thickness variation of cured laminate, tensile strength, flexural strength, and microscopic examination with 180X magnification were performed. Result and analysis of each measurement have been discussed below.

\section{RESULTS \& DISCUSSION}

\section{Flow Velocity}

Flow velocity depends on many parameters like viscosity of resin, diameter of inlet tube, pressure difference, number of layers, permeability of material, precompaction, etc. The flow velocity was observed during unsaturated flow with top camera as shown in Figure 3. 


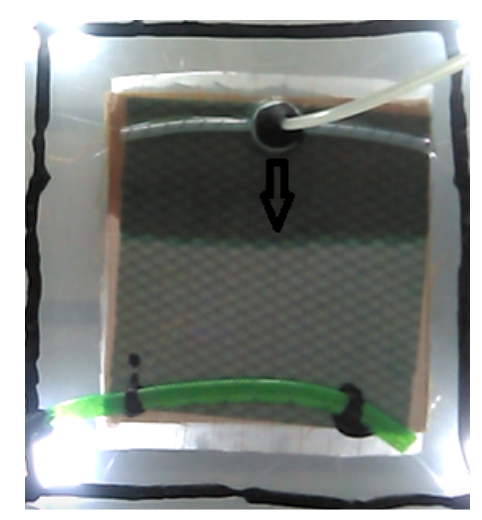

Figure 3. Flow velocity measurement from top camera.

Some important observations were noted during flow velocity study. It was observed that the resin flow velocity was reduced after degassing. The flow velocity was high at supply location and was gradually reducing at vacuum supply location. More leak rate was observed when number of layers increased from 5 to 15 near sealant tape. Flow gradient was observed between top and bottom layer in higher layered laminates. The flow velocity was high at top side and low at bottom side for 15 layered laminate. For a lesser number of layers, this phenomenon was not observed. It was noted that as the number of layers increased, the flow velocity decreased due to the thickness flow.

\section{Variation in Laminate Thickness}

Thickness was measured with mechanical comparator and dial gauge at total 25 locations all over the cured laminate. It was observed that as the number of layers increased, the variation in thickness increased. However, degassing did not generate much variation in laminate thickness. It was observed that the thickness of laminate was more at resin supply side than at vacuum side. The variation in thickness was observed due to location of vacuum supply and resin supply port on laminate. Figure 4 displays variation in average thickness for all six laminates.

$\begin{aligned} & \text { Average Thickness Variation } \\ & (\mathrm{mm})\end{aligned}$
$\begin{aligned} & \text { Average Thickness } \\ & (\mathrm{mm})\end{aligned}$

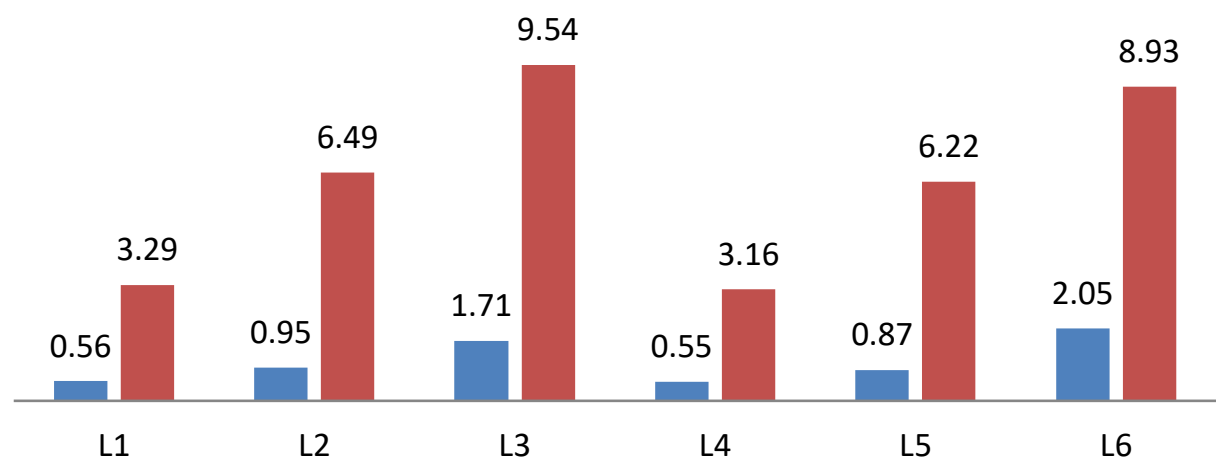

Figure 4. Average laminate thickness variations ( $\mathrm{mm})$ with and without degassing. 
The thickness variation helped know volume fraction variation and strength variation. Due to degassing, there was not much effect on thickness variation, but the properties have improved. This shows that the space occupied by voids in without degassing was now occupied by resin after degassing. A good bonding between matrix and reinforcement and better load transfer would have occurred after degassing.

\section{Tensile strength}

The test coupons sizes were as per type I, ASTM D638, for laminate thickness less than $7 \mathrm{~mm}$, and for laminate thickness more than $7 \mathrm{~mm}$, the test coupons sizes were as per type III. The testing was performed on universal testing machine (TINIUS OLSEN/L-Series H50KL) with speed of $2 \mathrm{~mm} / \mathrm{min}$. A total of five test coupons were taken from each laminate to perform tensile test. The average tensile strength of six laminates is shown in Figure 5. The maximum tensile strength was observed in laminate with a greater number of layers. From the results, it was observed that degassing process has helped reduce the void content, which may lead to an increase in the tensile strength.

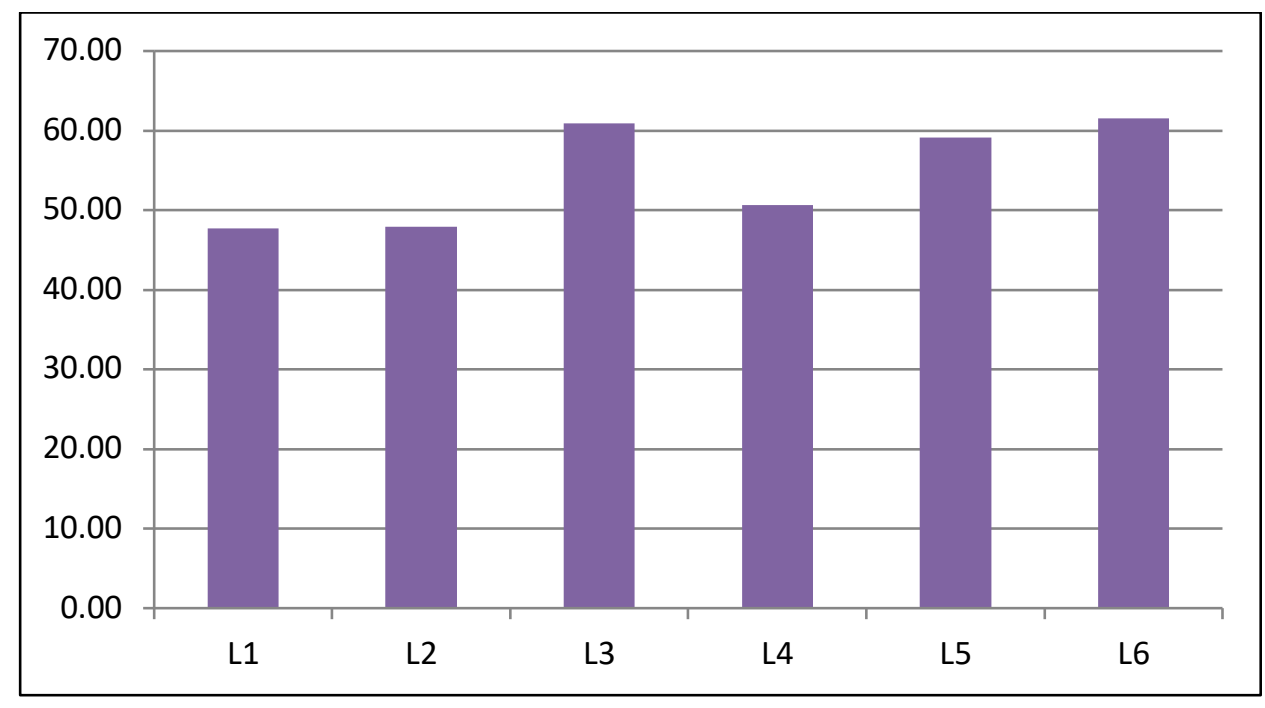

Figure 5. Average tensile strength.

\section{Flexural Strength}

Flexural strength was determined as per ASTM D790 standard on universal testing machine (TINIUS OLSEN/L-Series H50KL) with speed of $2 \mathrm{~mm} / \mathrm{min}$. Total five test coupons were taken from each laminate to perform the test. The average flexural strength of six laminates is shown in Figure 6. Due to degassing flexural strength increased. It was observed that as number of layers increased, the flexural strength decreased. 
Figure

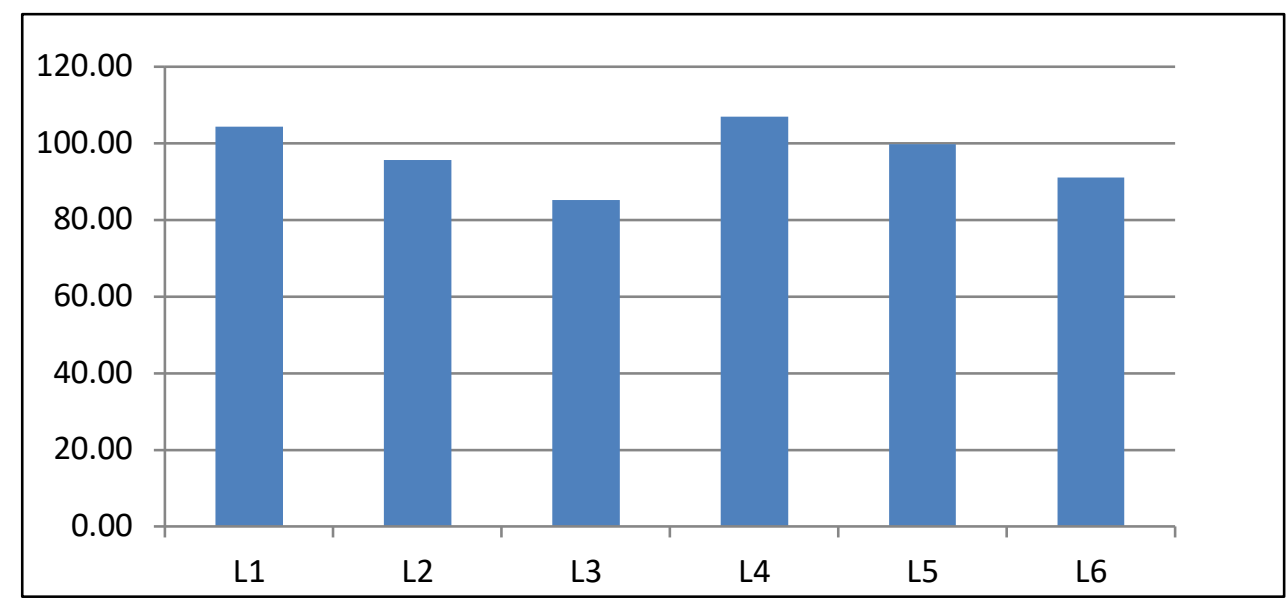

6.

\section{Microscopic Examination}

Average flexural strength.

During degassing air bubbles may have generated while mixing resin with hardener and due to exothermic reaction. Degassing was performed for polyester resin for full vacuum for 3 minutes at room temperature after mixing. Microscopic examination at $180 \mathrm{X}$ was performed for all the laminates to observe the effect before and after degassing as shown in Figure 7. It was clear from the micrographs that, due to degassing, the air bubbles reduced drastically, and because of this, better property was achieved. The laminate colour change was observed after degassing.

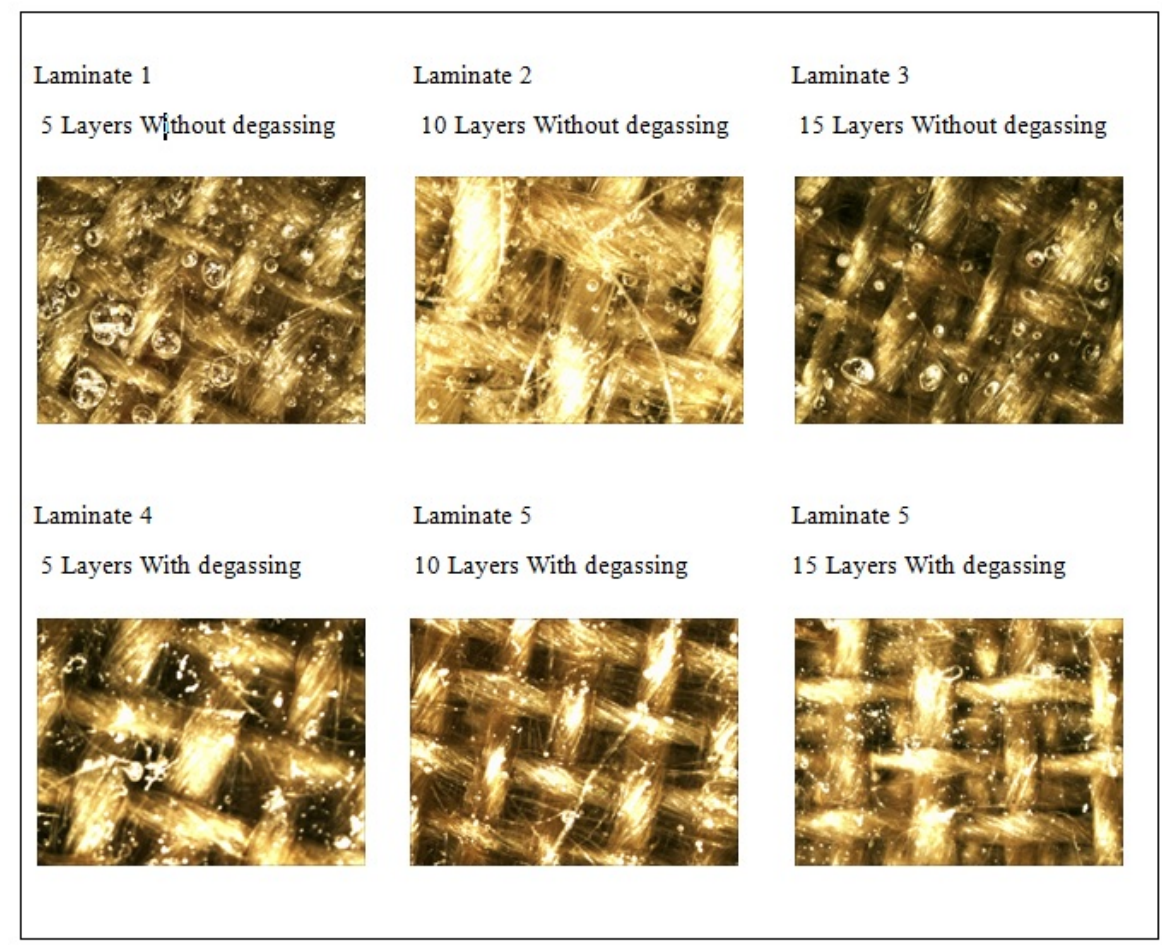

Figure 7. Air entrapments before and after degassing in laminates. 


\section{CONCLUSION}

The present work is focusing on effect of degassing process with changing number of layers. The following are findings of the present research work:

- The flow velocity was reduced after degassing. The flow velocity was higher at resin supply location and gradually reduced at vacuum supply side. The flow velocity gradient was observed. Top side layer was having higher velocity than bottom side layer. The same has been observed by Govignon et al. (2013).

- The laminate mechanical properties improved after degassing. It has been observed that the tensile strength has increased by $6 \%, 23 \%$, and $1 \%$ for 5,10 , and 15 layers with degassing. Flexural strength increased by $10 \%, 4 \%$, and $7 \%$ for 5,10 , and 15 layers, respectively, with degassing.

- Thickness variation during flow was observed for a greater number of layers during the flow. Th effect of degassing was not observed on thickness variation; however, as the number of layers increased, the thickness variation increased in cured laminates. An increase in the thickness variation by increasing the number of layers has been also observed by seal et al. (2001).

- Void inside the laminate had reduced drastically after degassing, which was observed by $180 \mathrm{X}$ microscope. The results are well in line with papers referred to during research review.

\section{ACKNOWLEDGMENT}

This work is carried out as a part of research project sanctioned by GUJCOST, Gandhinagar (GUJCOST/MRP/ 2016-2017/517) dated 27th June 2016.

\section{REFERENCES}

Afendi, M., Banks, W.M. \& Kirkwood, D., 2005. Bubble free resin for infusion process. Composites Part A: applied science and manufacturing. 36(6):739-746.

Amirkhosravi, M., Pishvar, M. \& Altan, M.C., 2019. Void reduction in VARTM composites by compaction of dry fiber preforms with stationary and moving magnets. Journal of Composite Materials. 53(6):769-782.

Bhatt, A.T., Gohil, P.P. \& Chaudhary, V., 2018, March. Primary Manufacturing Processes for Fiber Reinforced Composites: History, Development \& Future Research Trends. In IOP Conference Series: Materials Science and Engineering. 330(1): 012107).

Bolick R, 2000. Composite fabrication via the VARTM process. Triangle Polymer Technologies, Inc / North Carolina A\&T State University: STTR N064 - 040 - 0400

Brouwer, W.D., Van Herpt, E.C.F.C. \& Labordus, M, 2003. Vacuum injection moulding for large structural applications. Composites Part A: Applied Science and Manufacturing. 34(6):551-558.

Dewan, M.W., Hossain, M.K., Hosur, M. \& Jeelani, S., 2013. Thermomechanical properties of alkali treated jute-polyester/nanoclay biocomposites fabricated by VARTM process. Journal of applied polymer science. 128(6):4110-4123

Ghose, S., Watson, K.A., Cano, R.J., Britton, S.M., Jensen, B.J., Connell, J.W., Herring, H.M. \& Lineberry, Q.J., 2009. High temperature VARTM of phenylethynyl terminated imides. High Performance Polymers. 21(5):653-672. 
Govignon, Q., Bickerton, S., \& Kelly, P. A. 2013. Experimental investigation into the post-filling stage of the resin infusion process. Journal of composite materials, 47(12), 1479-1492.

Grimsley, B.W., Hubert, P., Song, X.L., Cano, R.J., Loos, A.C. \& Pipes, R.B., 2001. Flow and compaction during the vacuum assisted resin transfer molding process.

Heider, D. \& Gillespie Jr, J.W., 2010. VARTM Variability and substantiation. Center for Composite Materials, University of Delaware, Newark, DE 19716

Hindersmann, A., 2019. Confusion about infusion: an overview of infusion processes. Composites Part A: Applied Science and Manufacturing. 105583.

Kazmi, S. M. R., Govignon, Q., \& Bickerton, S. 2019. Control of laminate quality for parts manufactured using the resin infusion process. Journal of Composite Materials, 53(3), 327-343.

Kedari, V.R., Farah, B.I. \& Hsiao, K.T., 2011. Effects of vacuum pressure, inlet pressure, and mold temperature on the void content, volume fraction of polyester/e-glass fiber composites manufactured with VARTM process. Journal of Composite Materials. 45(26):.2727-2742.

Li, W., Krehl, J., Gillespie Jr, J.W., Heider, D., Endrulat, M., Hochrein, K., Dunham, M.G. \& Dubois, C.J., 2004. Process and performance evaluation of the vacuum-assisted process. Journal of composite materials. 38(20):1803-1814.

Park, C.H. \& Woo, L., 2011. Modeling void formation and unsaturated flow in liquid composite molding processes: a survey and review. Journal of reinforced plastics and composites. 30(11):957-977.

Prasad, T.M., 2004. Investigation of VARTM Processing of High Temperature RP-46 Resin System

Schledjewski, R. \& Grössing, H., 2017. Liquid Composite Molding: A Widely Used Group of FRPC Processing Techniques, but still a Challenging Topic. In Materials Science Forum. 879 :1715-1720.

Seal, A., Bose, N. R., Dalui, S. K., Mukhopadhyay, A. K., Phani, K. K., \& Maiti, H. S. 2001. Mechanical properties of glass polymer multilayer composite. Bulletin of Materials Science, 24(2), 197-201.

Van Oosterom, S., Allen, T., Battley, M. \& Bickerton, S., 2019. An objective comparison of common vacuum assisted resin infusion processes. Composites Part A: Applied Science and Manufacturing. 125:105528.

Yalcinkaya, M.A., Sozer, E.M. \& Altan, M.C., 2017. Fabrication of high quality composite laminates by pressurized and heated-VARTM. Composites Part A: Applied Science and Manufacturing. 102:336-346.

Yalcinkaya, M.A., Sozer, E.M. \& Altan, M.C., 2019. Effect of external pressure and resin flushing on reduction of process-induced voids and enhancement of laminate quality in heated-VARTM. Composites Part A: Applied Science and Manufacturing. 121: 353-364. 